\title{
IMPACT OF VARIOUS RESIN ADHESIVE STRATEGIES ON MICRO SHEAR BOND STRENGTH TO SOUND, CARIES- AFFECTED AND REMINERALIZED DENTIN SUBSTRATES: AN IN-VITRO ESEM ANALYSIS
}

\author{
Omaima H. Ghallab*, Heba M. Abd-Elaal ${ }^{* *}$ and Dina M. Abd-Elkhalik ${ }^{* * *}$
}

\begin{abstract}
Objectives: The aim of this in vitro study was to evaluate the micro shear bond strength of different adhesive system strategies to sound, artificially caries affected and remineralized dentin substrates.
\end{abstract}

Materials and Methods: Sixty bovine permanent incisors were used. The labial enamel was removed and a flat dentin surface was obtained. The dentin specimens were divided into three main groups (sound as a control, artificial caries affected and remineralized dentin groups). Four adhesive systems were applied over the different dentin substrates according to the directions of the manufacturers; (Futurabond M+, Single bond universal (universal adhesives used in self-etch mode, Futurabond DC (Dual- curing self etch bond with nanofillers and Solobond M (Etch and rinse adhesive). After preparation of the 240 micro tubules of resin composite (Filtek ${ }^{\mathrm{TM}}$ Z350XT (Flow able restorative), micro shear bond strength test was performed. The results were tabulated and statistically analyzed. Failure mode was detected for all the fractured dentin specimens using the stereomicroscope. ESEM evaluation was done for resin dentin interfaces for all types of adhesives.

Results: There was a statistically significant effect of dentin substrate, while the adhesive system type was not. One way ANOVA followed by Tukey HSD post hoc test showed that, the remineralized dentin recorded the highest micro shear bond strength value with Single Bond Universal followed by Futurabond M+. The artificial caries affected dentin showed the highest micro shear bond strength value with Solobond M followed by Futurabond DC, which also recorded the lowest micro shear bond strength result with remineralized dentin.

Conclusions: 1- Performance of the tested adhesives strategies was shown to be dentindependant.2- Dentin pretreatment with CPP-ACPF containing paste affects positively the microshear bond strength of Single bond universal and Futurabond M+ universal adhesives when used in self-etch mode.3-The specific chemical formula of the tested resin adhesives might coordinate with the demineralized dentin.

Key Words: Artificial caries affected dentin- Remineralized dentin- Universal adhesive-micro shear bond strength.

\footnotetext{
* Associate Professor of Operative Dentistry, Faculty of Dentistry, Ain-Shams University, Cairo, Egypt.

** Lecturer of Operative Dentistry, Faculty of Dentistry, Ain-Shams University, Cairo, Egypt.

*** Lecturer of Oral Biology, Faculty of Dentistry, Ain-Shams University, Cairo, Egypt.
} 


\section{INTRODUCTION}

Dental caries is still the most common problem in the dental clinic, affecting both enamel and dentin. Nowadays, application of the conservative concept during removal of the only diseased tissue should be done with great attention. Carious dentin is composed of two distinguished layers, as reported in Fusayama's research, infected outer layer and affected inner layer. Infected dentin should be completely removed as it is loaded with bacteria, highly demineralized and cannot be remineralized due to presence of irreversible denatured collagen fibers with absence of cross linking agents. On the other hand, affected dentin should be preserved as it is partially demineralized and the normal, bacterialfree, collagen fibers can be remineralized. ${ }^{(1-5)}$

As dentinal caries is a dynamic cycle of demineralization and remineralization, its mineral content, water and organic components are affected rendering the caries affected dentin (CAD) with different morphological, chemical and physical properties. Decrease in magnesium $(\mathrm{Mg})$ content which is an indicator for the loss of peritubular dentin matrix, followed by calcium (Ca) and phosphorus $(\mathrm{P})$ were remarkable in dentin caries. In addition, reducible cross-links of the collagen (but this can be reversible) and increase of water content that reaches to $14-53 \%$ were noticed. Despite water is increased, the dentin permeability of CAD decreased due to precipitation of mineral crystals in the lumen of dentinal tubules (whitlokite; large rhombohedral crystals of $\mathrm{Mg}$ ) which is less soluble than hydroxyapatite (HA). ${ }^{(1,4,6)}$

Bonding to CAD through formation of strong and durable hybrid layer is considered a clinical challenge. As the smear layer of CAD is thicker and enriched with organic content compared with those formed in sound dentin tissue ${ }^{(3,7)}$, the created hybrid layer is thicker because CAD is more liable to acid etching due to its partially demineralized condition leading to deeper demineralizing zone. ${ }^{(1,5,8-10)}$
The varieties and continuous advances in resin adhesive systems that differently deal with CAD may affect the clinical performance, the bond strength of the overlaying bonded restorations and their durability. The contemporary resin adhesives can be categorized to etch and rinse (three- step and twostep systems) and self-etch systems (SEA) (two step and one-step systems). When using etch and rinse systems on $\mathrm{CAD}$, the demineralizing intertubular dentin would enhance the effect of acid-etching step resulting in increased depth of demineralization. Such greater depths may not be fully infiltrated by the resin monomers. These unprotected collagen fibrils are prone to accelerated degradation by the action of matrix metalloproteinases (MMPs) affecting the bond strength outcome and durability of the bonded restorations. ${ }^{(5)}$

In the early 1990s, the concept of self-etch primer was evolved. It depends on the homogenous infiltration from the smear layer to the underlying affected tissue. Poor infiltration of thick smear layer of $\mathrm{CAD}$ resulted in non homogenous hybridization, and large amount of disorganized collagen smear layer could remain even when strong acid was used, because the acid can only solubilize the mineral content of the smear layer. This collagenous smear layer is impermeable impairing the homogenous infiltration of SEA that could affect the final bond strength of the restorations. ${ }^{(2,3)}$ Nanoadhesives are considered one of the revolutions of nanodentistry. They are solutions with non agglomerated nanoparticles thus producing high dentin and enamel bond strengths, increase shelf life, durable marginal seal, high stress absorption and fluoride release. (Futura bond DC, Voco, Germany) is an example and claimed to be the eighth generation. ${ }^{(1)}$

The latest new family of resin adhesives are called (Multimode) (Multipurpose) or (Universal). They can be applied either with etch and rinse (Two step) or self-etch technique (One or Two step) with a simple procedure and one bottle formula. 
Also, these multi-mode approaches enable the clinicians to use the adhesive with the mode of (Selective enamel etching) that combines the benefits of etch and rinse approach on enamel and self-etch approach on dentin tissue with additional chemical interaction with the HA remained in those substrates. The universal adhesives are considered to be highly complicated cocktails of many elements that were used in previous generations of adhesives. ${ }^{(12,13)}$ There is a shortage of knowledge in the literature about the performance of this new class of adhesives. ${ }^{(14)}$

One study reported that, the protocol used with universal adhesives did not affect the micro-tensile bond strength ${ }^{(15)}$, while another one revealed that the application of multimode adhesives in selfetch approach resulted in lower micro tensile bond strength when compared to etch and rinse approach. ${ }^{(13)}$ Using the one step SEA for bonding in etch and rinse mode deprives the benefit of chemical bonding with $\mathrm{HA}$, replacing the etching and infiltration by diffusion of incomplete infiltration of resin monomers within a thick demineralized collagen matrix that had deprived HA. ${ }^{(12)}$

According to adhesion-decalcification concept, the use of strong acids led to decalcification and dissolution of HA crystals that prevent the functional resin monomers to chemically interact with HA specially for the universal adhesives that contain 10-MDP which bonds chemically to HA. ${ }^{(12,15)}$ Also, the application of phosphoric acid prior to SEA was coupled with significant decrease in the bond strength to dentin. ${ }^{(16)}$ In previous literature, active application of SEA improved the bonding efficacy to dentin..$^{(17,18)}$ After mixing and dilution of the resin monomers to produce dentin adhesives, controversial data was still present regarding the bonding efficiency. Although HEMA (as a monofunctional resin monomer co-solvent) is used to improve wetting and prevent phase separation by homogenizing hydrophobic and hydrophilic monomers, HEMA may interfere the chemical reaction of MDP with HA. This may suggest that, the bonding efficiency and long term stability of the universal adhesives are not as immune as claimed by the manufacturer. ${ }^{(12,19,20)}$

The mechanical properties of CAD are inferior compared with those of sound dentin following demineralization and enzymatic degradation. However, the remineralization of dentin is more complex and less effective process due to absence of seeds of mineral crystals and is still a challenge. ${ }^{(21,22)}$ Repair of demineralized collagen fibrils by mineral implementation within the gaps between the collagen fibrils was tried by the application of topical remineralizing agents such as casein phosphopeptide-amorphous calcium phosphate fluoride (CPP-ACPF) known as MI paste plus $^{\mathrm{TM}(16,23-26)}$

$\mathrm{CPP}-\mathrm{ACPF}$ is a remineralizing agent derived from the milk and can promote high degree of remineralization in enamel as well as dentin compared to fluoride gel or fluoride tooth paste. ${ }^{(27)} \mathrm{It}$ has a great potential to modulate bioavailability of $\mathrm{Ca}$ and $\mathrm{P}$ levels by stabilization of ionic super saturation of $\mathrm{Ca}$ and $\mathrm{P}$ to enhance the remineralization process and can bind to positively and negatively charged ions. ${ }^{(28)} \mathrm{ACP}$ is the controller of the precipitation of CPP. Each molecule of CPP can bind up to $25 \mathrm{Ca}$ ions, $15 \mathrm{P}$ ions and five $\mathrm{F}$ ions. ${ }^{(28,29)}$ The effective period of application of CPP-ACPF for one week was reported. ${ }^{(30,31)}$ Prof. Eric Reynolds of the University of Melbourne developed the CPPACP technology. It had been launched in sugarless chewing gum and candy, recently, a sugar-free, water-based cream/paste. Combined CPP-ACP with $\mathrm{F}$ improved the remineralizing efficacy. ${ }^{(28,29)}$

In the literature, the effect of remineralizing efficiency of CPP-ACPF is still not clear as it revealed no significant effect on the bond strength to normal and CAD. ${ }^{(32)}$ While another study reported a high significant effect for normal dentin than CAD 
and the remineralized dentin. ${ }^{(33)}$ On the other hand, MI paste treated dentin samples had statistically higher bond strength than non-treated one. ${ }^{(34)}$

Although it was reported that, the immediate resin-dentin bond strength of adhesive systems is not affected by the method of caries induction, the lack of standardization of natural caries lesions led to technical difficulties for bonding assessment. Thus, artificial in-vitro caries induction models have been introduced under standardized conditions such as chemical methods; $\mathrm{PH}$ - cycling model that creates superficial dentin demineralization, resulting in a substrate with similar hardness when compared to the naturally $\mathrm{CAD}$ and creates a standardized substrate permitting fair comparisons among different resin adhesives and techniques. ${ }^{(35,36)}$

The adhesive potential strength of resin composite to CAD can be assessed by using of micro-method where small areas with limited sizes can be measured. ${ }^{(10,37)}$ Immediate 24- hour bond strength was preferable as the specimens of low values can be used as indicators and announcers for the predictable failures, because of stresses at the bonded interfaces high lighting for the accelerated hydrolysis and enzymatic degradation. ${ }^{(5)}$

The controversy in researches regarding the great difference in bond strength to dentin may be due to lack of detailed knowledge about the nature of dentin, age of tooth, type of adhesive used, the manner of application and the test method. In the present literature paying attention to the interaction of the universal adhesives to different dentin substrates has not been extensively investigated. So, deeper knowledge in this subject could be helpful for creating clinically long lasting bonded restorations. Thus, the objective of this study was to test the hypotheses; (1): All dentin substrates (sound, caries affected, remineralized) bond equally to different adhesive strategies. (2): There is no difference between total etch, dual cure self-etch and universal adhesives in self etch mode in bonding efficacy to these respective dentin substrates.

\section{MATERIALS AND METHODS}

\section{Teeth selection and specimen preparation:}

A total of sixty freshly extracted permanent bovine sound incisors were selected. The roots of the teeth were removed at the cervical lines in addition to the incisal one thirds using watercooled disc mounted in a high speed hand piece (DEMCO, USA). The pulp was extirpated and the pulp chambers were irrigated with saline. The labial enamel was removed to obtain a labial flat dentin surface with an area of $10 \mathrm{~mm}^{2}$. The teeth had been stored at $4^{\circ} \mathrm{C}$ in thymol solution until used for no longer more than one month. ${ }^{(38)}$. To produce a standardized smear layer, the flattened labial dentin surfaces were polished with \#600-grit silicon carbide abrasive paper under running water for 60 seconds.

\section{Grouping of the specimens:}

The specimens were divided into three main groups (20 each):

Group (1): Sound dentin (SD): is considered the control group and stored in periodically renewed deionized water.

Group (2): Dentin specimens had artificially induced caries (CAD) by PH cycling method.

Group (3): Dentin specimens treated with MI paste plus after the demineralization (RCAD).

Each group was further subdivided into four smaller groups (five each) according to the type of adhesive system used into:

Subgroup (a): Dentin specimens were bonded with Futurabond M+ (FM+) (universal adhesive used in self-etch mode).

Subgroup (b): Dentin specimens were bonded with Single bond universal (SBU) (universal adhesive used in self-etch mode).

Subgroup (c): Dentin specimens were bonded with Futurabond DC (FDC) (Dual- curing self etch bond with nanofillers). 
Subgroup (d): Dentin specimens were bonded with Solobond M (SM) (Etch and rinse adhesive).
All materials used in this study, their active ingredients, batch number, manufacturer and application mode are listed in table (1)

TABLE (1) The materials, active ingredients, batch number, manufacturer and application mode:

\begin{tabular}{|c|c|c|c|c|}
\hline Material & Active ingredients & Batch no & Manufacturer & Application mode \\
\hline $\begin{array}{l}\text { GC MI } \\
\text { paste Plus } \\
\text { (Remineralizing } \\
\text { agent) }\end{array}$ & $\begin{array}{l}\text { Casein phosphopeptides } \\
\text { (CPP) and Amorphous } \\
\text { calcium phosphate (ACP) } \\
\text { i.e. Recaldent }{ }^{\text {TM }} \text {. } \\
\text { Sodium fluoride }(0.2 \% \text {, } \\
\text { 900ppm) }\end{array}$ & $150306 \mathrm{~V}$ & $\begin{array}{l}\text { GC } \\
\text { corporation } \\
\text { Japan }\end{array}$ & $\begin{array}{l}\text { 1-Apply the paste for } 5 \text { minutes, left undisturbed. } \\
\text { 2- Rinse with deionized water until the paste was } \\
\text { completely removed. }\end{array}$ \\
\hline $\begin{array}{l}\text { Futurabond } \\
\text { M+(universal } \\
\text { adhesive) }\end{array}$ & $\begin{array}{l}\text { BIS-GMA*, Acidic } \\
\text { monomer (10-MDP) } \\
{ }^{*}, \text { UDMA }^{*}, \text { HEMA*, } \\
\text { Ethanol, catalyst, } \\
\text { BHT }{ }^{*} \text {,Pyrogenic silicic } \\
\text { acid. }\end{array}$ & 1522066 & $\begin{array}{l}\text { VOCO } \\
\text { Cuxhaven, } \\
\text { Germany }\end{array}$ & $\begin{array}{l}\text { 1-Apply the adhesive evenly and rub it for } 20 \\
\text { seconds with a disposable applicator. } \\
\text { 2-Gently dry off the adhesive for } 5 \text { seconds with } \\
\text { oil-free air to remove the solvent. } \\
\text { 3-Light cure for } 10 \text { seconds with LED curing unit. }\end{array}$ \\
\hline $\begin{array}{l}\text { Single Bond } \\
\text { Universal } \\
\text { (single dose } \\
\text { universal } \\
\text { adhesive) }\end{array}$ & $\begin{array}{l}\text { 10-MDP dimethacrylate } \\
\text { resins, HEMA, } \\
\text { Vitrebond Copolymer, } \\
\text { Silane,Ethanol, Water, } \\
\text { Filler, Photoinitiator, } \\
\text { pH=2.7 }\end{array}$ & 598528 & $\begin{array}{l}\text { 3MESPE } \\
\text { USA }\end{array}$ & $\begin{array}{l}\text { 1- Apply the adhesive evenly and rub it for } 20 \\
\text { seconds with a disposable applicator. } \\
\text { 2- Gently dry off the adhesive for } 5 \text { seconds with } \\
\text { oil-free air to remove the solvent until it no longer } \\
\text { moves. } \\
\text { 3- Light cure for } 10 \text { seconds with LED curing unit }\end{array}$ \\
\hline $\begin{array}{l}\text { Futurabond DC } \\
\text { (Single dose) } \\
\text { dual curing self- } \\
\text { etch bond with } \\
\text { nanofillers }\end{array}$ & $\begin{array}{l}\text { Liquid 1: Acidic } \\
\text { adhesive monomer. BIS- } \\
\text { GMA.2-hydroxyethyle } \\
\text { methacrylate. } \\
\text { Liqiud 2: Ethanol, } \\
\text { initiator. Nanofillers. } \\
\text { pH=2 }\end{array}$ & 1548356 & $\begin{array}{l}\text { VOCO } \\
\text { Cuxhaven, } \\
\text { Germany }\end{array}$ & $\begin{array}{l}\text { 1-Inject liquid } 1 \text { in liquid } 2 \text { in } 1: 1 \text { ratio and stir } \\
\text { well to create a homogenous mixture. } \\
\text { 2- Apply the adhesive evenly and rub it for } 20 \\
\text { seconds with a disposable applicator. } \\
\text { 3- Gently dry off the adhesive for } 5 \text { seconds with } \\
\text { oil-free air. } \\
\text { 4-Light cure for } 10 \text { seconds with LED curing unit. }\end{array}$ \\
\hline $\begin{array}{l}\text { Solobond } \mathrm{M} \\
\text { (etch and rinse } \\
\text { adhesive) }\end{array}$ & $\begin{array}{l}\text { BIS-GMA, HEMA, BHT, } \\
\text { Acetone, Organic acids. }\end{array}$ & 1508459 & $\begin{array}{l}\text { VOCO } \\
\text { Cuxhaven, } \\
\text { Germany }\end{array}$ & \multirow[t]{2}{*}{$\begin{array}{l}\text { 1- Etch the dentin surface for } 15 \text { seconds. } \\
\text { 2- Rinsing for } 20 \text { seconds. } \\
\text { 3- Gentle dry the surface to obtain a moist one. } \\
\text { 4- Apply the adhesive; allow it undisturbed to } \\
\text { react for } 30 \text { seconds. } \\
\text { 5- Disperse it with a faint air jet. } \\
\text { 6- Light cure for } 20 \text { seconds with LED curing unit. }\end{array}$} \\
\hline Alpha-Etch & $\begin{array}{l}37 \% \text { phosphoric acid } \\
\text { gel, water, thickener, } \\
\text { surfactant, colorant }\end{array}$ & T228GE & $\begin{array}{l}\text { Dental } \\
\text { Technologies, } \\
\text { USA }\end{array}$ & \\
\hline $\begin{array}{l}\text { Filtek }{ }^{\mathrm{TM}} \\
\mathrm{Z} 350 \mathrm{XT} \text { ( Flow } \\
\text { able restorative) } \\
\text { Shade A3 }\end{array}$ & $\begin{array}{l}\text { Silica }(20 \mathrm{~nm}), \text { Zirconia } \\
(4-11 \mathrm{~nm}), \text { BIS-GMA, } \\
\text { UDMA, BIS-EMA*, } \\
\text { TEDEMA* }\end{array}$ & 662643 & $\begin{array}{l}\text { 3MESPE } \\
\text { St. Paul, MN } \\
\text { USA }\end{array}$ & \\
\hline
\end{tabular}

*BIS-GMA: Bisphenol A Diglycidyl Ether Dimethacrylate *10-MDP: 10-Methacryloyloxydecyl Dihydrogen Phosphate

*UDMA: Urethane Dimethacrylate

*BHT: Butylated Hydroxytoluene

*TEDEMA: Tri-ethylene Glycol Dimethacrylate
*HEMA: 2-Hydroxyethyle Methacrylate

*BIS-EMA: Bisphenol-A-Polyethylene Glycol Diether Dimethacrylate 


\section{Artificial caries affected dentin production by} PH-cycling method:

The cervical parts of 40 specimens were sealed with self cured epoxy resin (Acrostone, cold cure, Egypt) and coated with two layers of acid-resistant varnish (Colorama, Maybelline, Color show, France) leaving only the labial dentin surface exposed.

The specimens were totally immersed individually in $10 \mathrm{~mm}$ of demineralizing solution which was freshly prepared, for eight hours and followed by immersion in the same volume of freshly prepared remineralizing solution for the remaining 16 hours. The immersion procedures of demineralization and remineralization were carried out for 14 days at room temperature without agitation. The immersing solutions were renewed at each cycle. These solutions were prepared in Analytical chemistry Department, Faculty of Science, AinShams University. The chemical composition of the demineralizing and remineralizing solutions is presented in table (2). ${ }^{(35,39)}$

TABLE (2): The chemical composition and $\mathrm{pH}$ of the demineralizing and remineralizing solutions:

\begin{tabular}{|l|l|}
\hline Demineralizing solution & Remineralizing solution \\
\hline $2.2 \mathrm{mM} \mathrm{CaCl} 2,2.2 \mathrm{mM}$ & $1.5 \mathrm{mMCaCl} 2$, \\
$\mathrm{NaH} 2 \mathrm{Po} 4,50 \mathrm{mMAcetic}$ & $0.9 \mathrm{mMNaH} 2 \mathrm{Po} 4$, \\
acid. & $0.15 \mathrm{mMKcl}$. \\
Adjusted $\mathrm{pH}$ of 4.8 & Adjusted $\mathrm{pH}$ of 7.0 \\
\hline
\end{tabular}

After 14 days, the specimens were carefully rinsed with deionized water to remove all remnants of the immersing solutions and stored in fresh deionized water.

\section{Remineralization of artificial caries affected den- tin specimens:}

A total of 20 specimens from the specimens with artificial caries affected dentin were randomly selected for remineralization with MI paste plus (GC, Japan) with vanilla flavor. Single application of approximately $0.5 \mathrm{~mm}$ layer of the paste was spread over the exposed CAD surface using a clean gloved finger for each specimen and left for five minutes undisturbed. ${ }^{(32)}$

Then, the remineralizing agent was rinsed with deionized water until all remnants were removed and re-stored in daily renewed deionized water. This procedure was repeated once daily for seven days.

\section{The bonding procedures:}

A total of 48 specimens representing the groups of $\mathrm{SD}, \mathrm{CAD}$ and RCAD (16 each) were reassigned to four groups (four each) according to the adhesive system used as mentioned before. All adhesives were strictly applied matching the directions of their manufacturer as described in table (1). All specimens were embedded individually in acrylic resin blocks to receive the bonding procedures.

\section{Preparation of micro shear resin composite cylinders:}

A total of 240 transparent polyvinyl micro tubules with inner diameter of $(1 \mathrm{~mm})$ and height of $(1 \mathrm{~mm})$ were adjusted over the cured adhesives by LED curing unit (Eli par ${ }^{\mathrm{TM}}$ S10 LED Curing Light (1200 mw/ $\mathrm{cm}^{2}$ intensity) (3M ESPE, USA). Light intensity was measured periodically using radiometer (Demetron 100, Kerr, Midelton, USA) at the beginning of each group. Each dentin specimen received five micro tubules over the area of $10 \mathrm{~mm}^{2}$. Each micro tubule was filled with a flow able nanohybrid resin composite material and light cured for 20 seconds.

\section{Micro shear bond strength ( $\mu \mathrm{SBS})$ testing:}

After 24 hours storage in deionized water, the microtubules were sectioned to expose the composite micro-cylinders using sharp scalpel blade number 11. Excess adhesive around each micro-cylinder was scrapped out using the same surgical blade to limit the bonding surface area. The micro-cylinders were examined by a magnifying lens for any defects at the interface. 
Each specimen with the bonded composite micro-cylinders was secured with tightening screws to the lower fixed compartment of Universal testing machine (Model LRX-plus; Lloyd Instruments Ltd., Fareham, UK) with a load cell of 5 N. A loop prepared from an orthodontic wire $(0.014 \mathrm{~mm}$ in diameter) was wrapped around the bonded micro cylinder assembly as close as possible to the base of the micro cylinder and aligned with the loading axis of the upper movable compartment of the testing machine.

A shearing load with tensile mode of force was applied via the testing machine at a crosshead speed of $0.5 \mathrm{~mm} / \mathrm{min}$. The relatively slow crosshead speed was selected in order to produce a shearing force that resulted in debonding of the micro-cylinder along the substrate/adhesive interface. The load required to debonding was recorded in Newton and the data were recorded using computer software (NexygenMT Lloyd Instruments Ltd., Fareham, UK).

Micro-Shear bond strength ( $\mu$ SBS) calculation

The load at failure was divided by bonding area to express the bond strength in MPa:

$$
\tau=\mathbf{P} / \pi \mathbf{r}^{2}
$$

Where; $\boldsymbol{\tau}=$ bond strength (in $\mathrm{MPa}$ )

$$
\begin{aligned}
& \mathbf{P}=\text { load at failure (in } \mathrm{N} \text { ) } \\
& \boldsymbol{\pi}=3.14 \\
& \mathbf{r}=\text { radius of micro-cylinder (in } \mathrm{mm} \text { ) }
\end{aligned}
$$

The results were collected, tabulated and statistically analyzed.

\section{Statistical analysis:}

Two- way ANOVA analysis of variance and Tukey HSD post hoc test were used at a significant level of 5\%. The data was expressed in (MPa) and the Statistical analysis was carried using SPSS program (21 $1^{\text {st }}$ editions, IBM Corporation, New York, USA).

\section{Stereomicroscopic analyses of failure modes of micro shear bond strength testing:}

The failure modes were evaluated for each specimen under the stereomicroscope (at 20X (OLYMPUS C-W95, SZ-PT OLYMPUS-JAPAN) and categorized as cohesive failure which occurred entirely within the dentin substrate or the resin composite material. Mixed failure occurred at dentin/resin interface including cohesive failure of one of the substrates. Adhesive failure occurred at dentin/resin interface. The failure modes were counted and tabulated for each group.

\section{Environmental Scanning Electron Microscopic (ESEM) Analysis:}

A total of 12 remaining dentin specimens representing the groups of $\mathrm{SD}, \mathrm{CAD}$ and RCAD (four specimens each) were prepared for evaluation of ESEM investigation. The specimens were removed from the deionized water, gently dried with oil-free compressed air, and the four resin adhesives were applied according to the manufacturer directions as mentioned in table(1). A layer of $2 \mathrm{~mm}$ thickness of hybrid, visible light cure resin composite material (Prime-Dent, USA) was smeared over the entire dentin surface by a double ended plastic instrument and overlapped light cured by LED curing unit for 20 seconds. Multiple cuts were performed for each specimen in a labio-palatal direction to obtain four slabs with a thickness of $2 \mathrm{~mm}$ composed of hybridized dentin with overlying resin composite material. Each four slabs formed a group represented the type of dentin and the different adhesive systems used. Each dentin slab was investigated under ESEM (SEM Model Quanta 250 FEG (Field Emission Gun) attached with EDX Unit (Energy Dispersive X-ray Analyses) with accelerating voltage $30 \mathrm{KV}$, magnification $14 \mathrm{x}$ up to 1000000 and resolution for Gun.1n) FEI company, Netherlands) to evaluate the resin-dentin interfaces of all groups. 


\section{RESULTS}

\section{A) Micro shear bond strength results:}

The shear bond strength data (MPa) for each dentin substrate and adhesive type are presented in Table (3). Both dentin treatments (demineralization and remineralization) significantly improved the shear bond strength of all adhesives compared to sound dentin (control), while the type of adhesive did not affect the shear bond strength.

One way ANOVA followed by Tukey HSD post hoc test showed that remineralized dentin recorded significantly higher micro shear bond strength with both universal adhesives (Single bond universal and Futurabond $\mathrm{M}+)$ used in the study $(18.137 \pm 4.543$ and16.760 $\pm 4.275 \mathrm{MPa}$ respectively) compared to sound dentin but did not differ significantly with demineralized dentin, also demineralized dentin and sound dentin did not differ significantly.

Demineralized dentin recorded significantly higher micro shear bond strength with Futurabond DC $(16.967 \pm 3.556 \mathrm{MPa})$ compared to sound and remineralized dentin which did not differ significantly from each other. While, Solobond M with demineralized dentin recorded significantly higher shear bond strength $(17.097 \pm 2.162 \mathrm{MPa})$ compared to sound and remineralized dentin which differed significantly from each other.

Regarding the effect of adhesive, One way ANOVA followed by Tukey HSD post hoc test showed that, single bond universal produced significantly higher micro shear bond strength to remineralized dentin $(18.137 \pm 4.543 \mathrm{MPa})$ compared to other adhesives, however, there was no significant differences in shear bond strength to sound (control) or demineralized dentin between all adhesives.
TABLE (3): Micro shear bond strength (MPa) means and standard deviations for all experimental groups $(*)$ :

\begin{tabular}{|c|c|c|c|}
\hline & $\begin{array}{c}\text { Control } \\
(\text { S D. }\end{array}$ & CAD & R CAD \\
\hline Futurabond & $11.028 \pm$ & $13.451 \pm$ & $16.760 \pm$ \\
M+ & $2.681^{\mathrm{Aa}}$ & $4.343^{\mathrm{Aab}}$ & $4.275^{\mathrm{ACb}}$ \\
\hline Futurabond & $11.711 \pm$ & $16.967 \pm$ & $10.648 \pm$ \\
DC & $3.659^{\mathrm{Aa}}$ & $3.556^{\mathrm{Ab}}$ & $3.887^{\mathrm{Ba}}$ \\
\hline Single bond & $10.559 \pm$ & $14.287 \pm$ & $18.137 \pm$ \\
Universal & $3.594^{\mathrm{Aa}}$ & $3.335^{\mathrm{Aab}}$ & $4.543^{\mathrm{Cb}}$ \\
\hline \multirow{2}{*}{ Solobond M } & $11.226 \pm$ & $17.097 \pm$ & $13.902 \pm$ \\
& $2.014^{\mathrm{Aa}}$ & $2.162^{\mathrm{Ab}}$ & $2.349^{\mathrm{ABc}}$ \\
\hline
\end{tabular}

(*) Different superscript capital letters indicate differences between columns. Different superscript lower case letters indicate statistically significant differences between rows $(p<0.05)$

Two-way ANOVA Table (4) revealed that, the type of dentin substrate has a significant effect on the micro shear bond strength, while the adhesive material has no significant effect on the micro shear bond strength values. The interactions between the two independent variables (dentin substrate and adhesives) had a significant effect on the micro shear bond strength.

TABLE (4): Two-way Analysis of Variance for the Effect of Type of Dentin Substrate, Adhesive Materials, and Their Interaction on the Shear Bond Strength.

\begin{tabular}{|l|r|r|r|r|r|}
\hline \multicolumn{1}{|c|}{ Source } & \multicolumn{1}{c|}{ SS } & \multicolumn{1}{c|}{ df } & \multicolumn{1}{c|}{ MS } & F & Sig \\
\hline Dentin Substrate & 526.704 & 2 & 263.352 & 21.887 & 0.0001 \\
\hline $\begin{array}{l}\text { Adhesive } \\
\text { Materials }\end{array}$ & 30.031 & 3 & 10.010 & 0.832 & 0.479 \\
\hline $\begin{array}{l}\text { Dentin Substrate } \\
\text { * Adhesive } \\
\text { Materials }\end{array}$ & 498.605 & 6 & 83.101 & 6.906 & 0.0001 \\
\hline Error & 1588.272 & 132 & 12.032 & & \\
\hline Total & 30124.765 & 144 & & & \\
\hline
\end{tabular}

df: degrees offreedom, MS: mean square, Sig: significance (probability level), SS: sum of squares. 


\section{B) Stereomicoscopic analysis of failure modes:}

TABLE (5): Counting of the failure modes of different dentin substrates:

\begin{tabular}{|l|l|l|}
\hline Dentin groups & Adhesive Failure & Mixed Failure \\
\hline SD (F DC) & 12 & 8 \\
\hline SD (SBU) & 13 & 7 \\
\hline SD (FM+) & 13 & 7 \\
\hline SD (SM) & 16 & 4 \\
\hline CAD (FDC) & 13 & 7 \\
\hline CAD (SBU) & 15 & 5 \\
\hline CAD (F M+) & 12 & 8 \\
\hline CAD (SM) & 14 & 6 \\
\hline RCAD (FDC) & 11 & 9 \\
\hline RCAD (SBU) & 17 & 3 \\
\hline RCAD (FM+) & 16 & 4 \\
\hline RCAD (SM) & 13 & 7 \\
\hline
\end{tabular}

\section{C) Micro-morphological results of the resin-den- tin interface with ESEM:}

\section{Group $1:(S D)$}

Dentinal tubules showed regular, variable outlines with numerous lateral branching. The peritubular dentin cuff seemed more or less circular in shape. The intertubular dentine appeared normal. Some resin tags impregnations were also obvious and the hybrid layer appeared uniform and continuous. Fig.4.

\section{Group (2): (CAD)}

In artificial caries affected dentine group, the dentinal tubules orifices showed irregular outlines with apparent widening of dentinal tubules to the extent of being connected to some of the neighboring lateral branches. Obvious disappearance of some areas of peritubular dentine cuff could be seen which resulted in appearance of some of the resin tags lengths. The resin tags impregnations were numerous below the hybrid layer which seemed thicker. The intertubular dentine showed apparent decrease in thickness than control .Fig.5

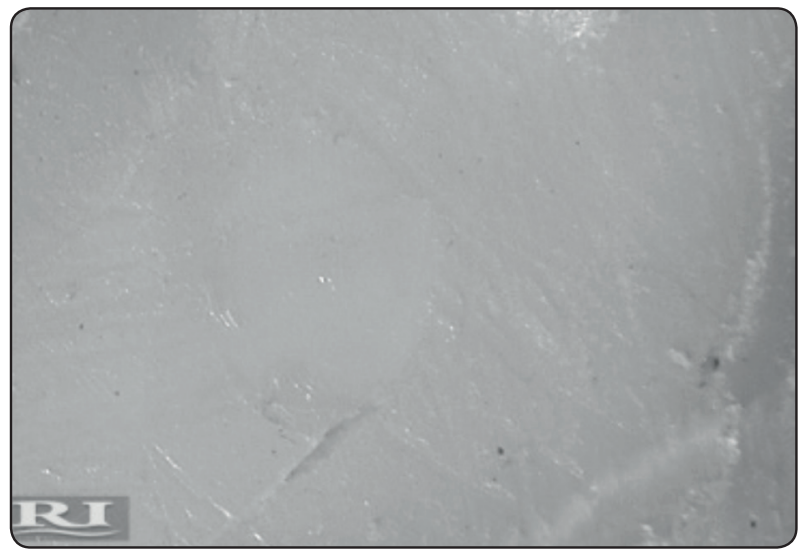

Fig. (1): Stereomicroscopic image representing adhesive failure at resin tooth interface

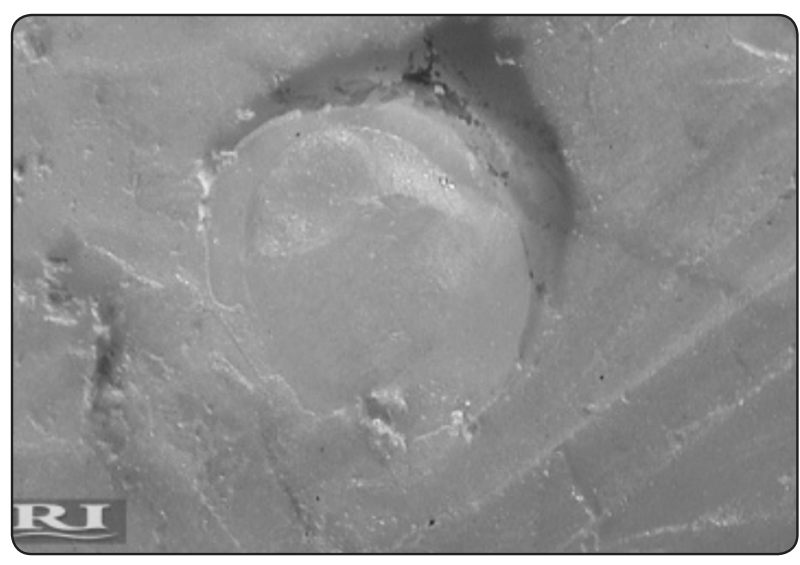

Fig. (2): Stereomicroscopic image representing Mixed failure (adhesive and cohesive failure in resin composite)

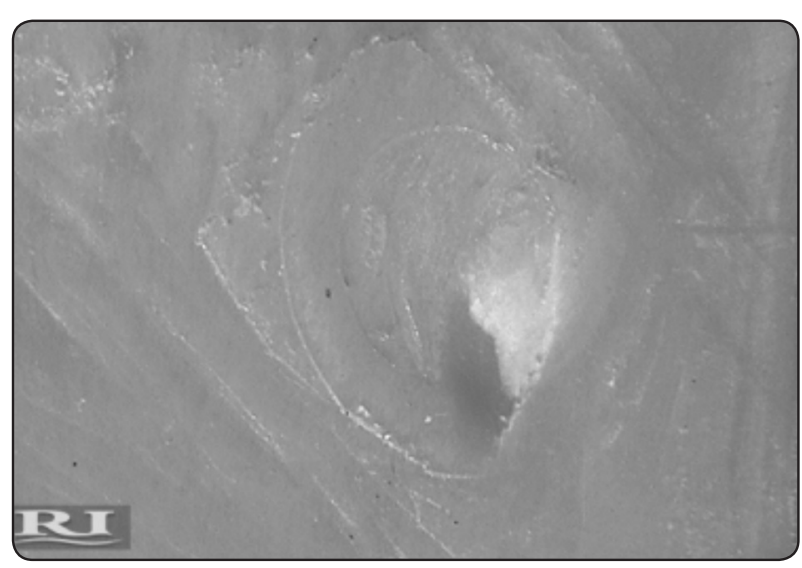

Fig. (3): Stereomicroscopic image representing mixed failure (adhesive and cohesive failure in dentin) 


\section{Group 3: (R CAD)}

ESEM of RCAD FDC presented a continuous, uniform thick hybrid layer .Partial restoration of dentinal tubules outline and very few resin tags with partial occlusion of few dentinal tubules was observed. While RCAD FM and RCAD SBU showed many resin tags impregnations penetrating into the dentinal tubules. Partial restoration of some tubular outlines was also observed. Apparent decrease in the diameter of dentinal tubules and partial occlusion of some tubules was also noticed. Few resin tags were also present in RCAD SM.Fig.6
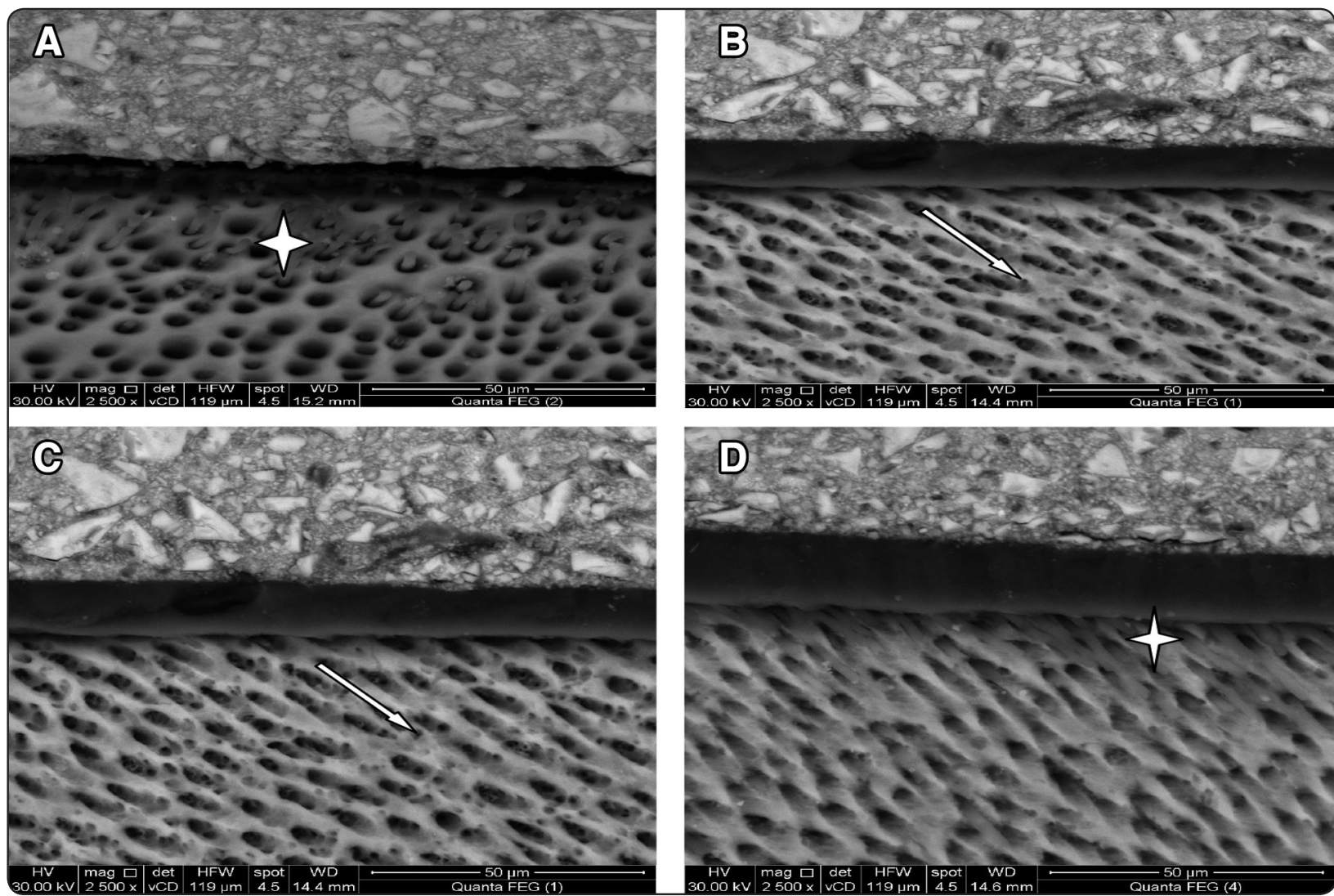

Figure (4): ESEM photomicrograph (x2500) of sound dentin (SD) hybridized with: (A): FDC (B): FM + which note: some resin tags (stars), lateral branches (white arrow), (C): SBU, (D): SM.

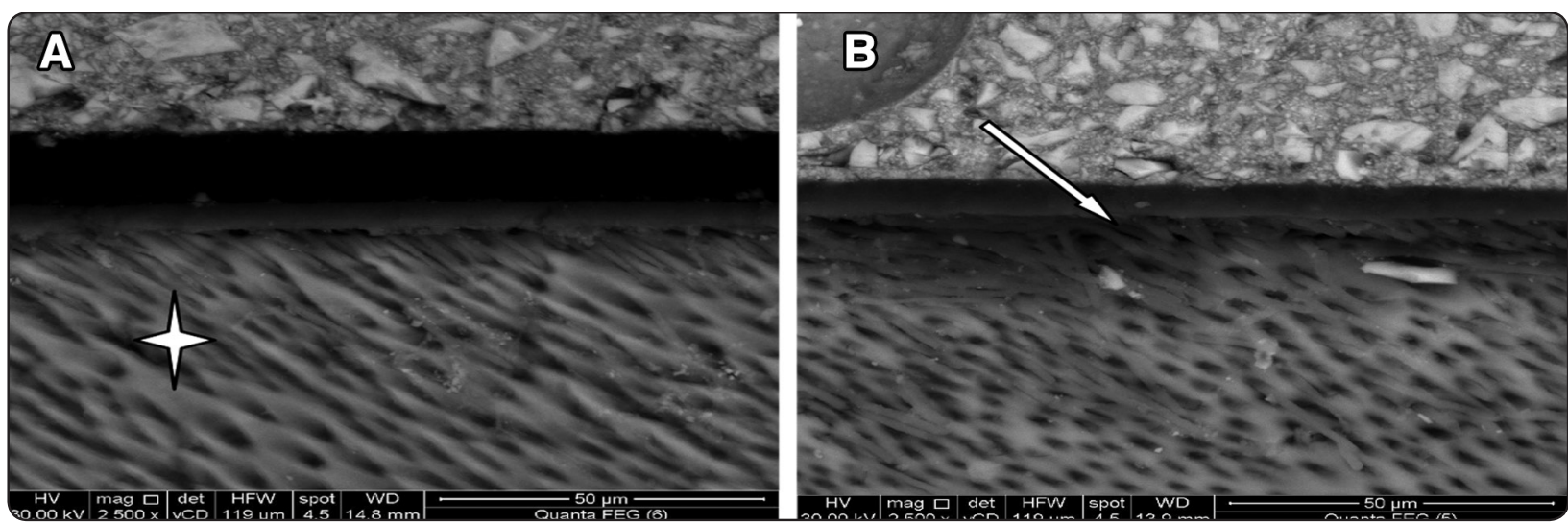



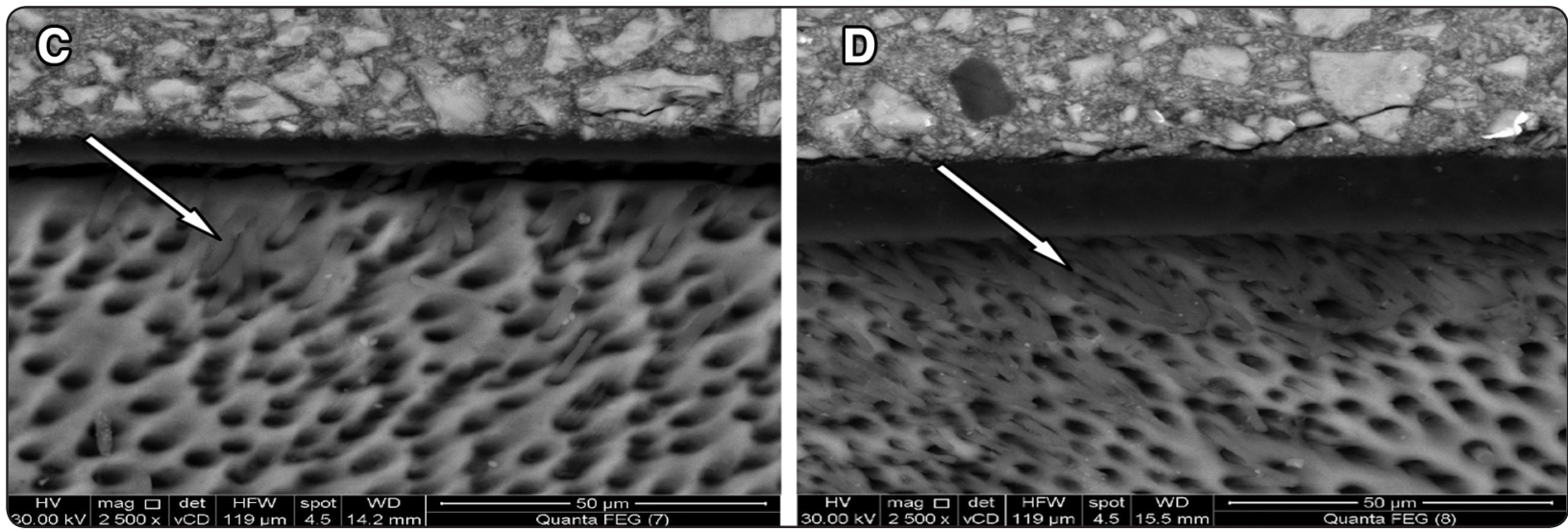

Fig. (5): ESEM photomicrograph (x2500) of caries affected dentin CAD hybridized with (A): FDC (B): FM + (C): SBU (D): SM showing widening of dentinal tubules (A):(star), numerous resin tags (white arrows)
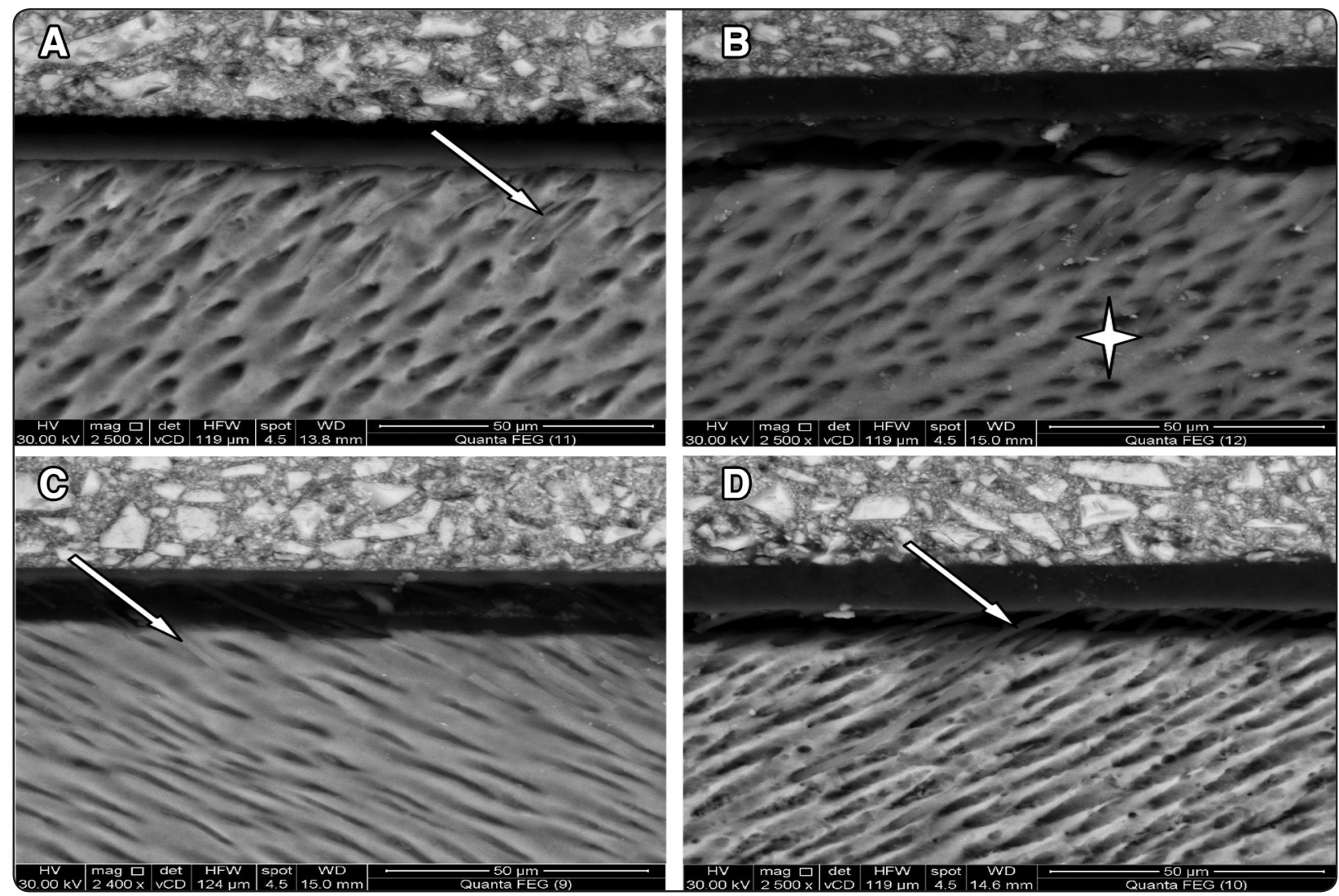

Figure (6): ESEM photomicrograph (x2500) of remineralized caries affected dentin RCAD hybridized with (A) FDC showing few resin tags (white arrow) (B) FM+ partial occlusion of tubules(star) (C) SBU numerous resin tags (D) SM showing some resin tags (white arrows). 


\section{DISCUSSION}

Demineralization and remineralization cycles are dominant during the development of caries process ${ }^{(4)}$. Remineralization of CAD by remineralizing agents as MI paste plus provided more net minerals and could assist in conserving the tooth structure and better dentin thickness. ${ }^{(31)}$ The improvement of dental adhesives to simplify the steps of application with maintaining of high bond quality is continuous. Regardless of the number of steps required, homogenous and complete infiltration of the hydrophilic monomer within the porous dentin substrate to form a hybridized resin dentin layer was reported to be an important common feature in effective resin-dentin interface bonding. ${ }^{(40)}$

Resin adhesive systems and procedures have undergone revolutionary changes in the last decade. The target of the advance is to enhance the durability of the bond between tooth structure and the bonded restorations. A transitional layer that facilitates efficient bonding via a complex interaction of tissue-adhesive interface is still remaining one of the critical challenges for research. Measurement of how strong this bonding interface is the main objective of bond strength test. ${ }^{(11)}$ In this study, bovine teeth were used as they were easier to be collected and to control the age, sclerosis and the amount of substrate removal. $\mathrm{pH}$ cycling method was to be close simulating the natural caries process with the limitations of not being replicated as invivo condition and the complicated dynamic process in the oral cavity ${ }^{(31,36)}$

The results of this in-vitro study showed a significant effect of dentin type which was consistent with the studies ${ }^{(33,36,39,41)}$ and insignificant influence of adhesive system types which was also in agreement with Yoshiyama et al, $2002{ }^{(41)}$, while their interaction was significant as shown in table (4). According to the obtained results, the first hypothesis was rejected and the second one was accepted.
Regarding the dentin type, RCAD showed the highest significant micro shear bond strength values for the adhesives Single bond universal and Futurabond $\mathrm{M}+(18.137 \pm 4.543 \mathrm{MPa}$ and16.760 $\pm 4.275 \mathrm{MPa}$ respectively) as shown in table (3) compared to the non treated dentin specimens SD without significant difference between the two adhesives. The key reason for their performance is the chemical compositions of those adhesives as their $\mathrm{pH}$ are nearly around 2 and both contain 10-MDP. The mild $\mathrm{pH}$ might cause a superficial demineralization of the RCAD kept the residual HA still attached to the collagen with a sufficient amount. 10-MDP is responsible for the chemical interaction with HA crystals forming a stable nano layer that could form a phase strengthened the resin dentin interface. Increasing the minerals by more gained calcium bioavailability for chemical binding due to the remineralization influence led to the increase in bond strength values. Active application of the two adhesives also might enhance the impregnation of the resin monomers into RCAD. Besides the synergistic effect of mechanical interlocking as despite the importance of the chemical interaction with the tooth minerals, the micro-mechanical interlocking is still also a crucial factor in determining the strength of immediate bonding. ${ }^{(14,17,18,34)} 10-\mathrm{MDP}$ as an acidic monomer might increase the micromechanical roughening of the dentin surface and hybridization during the polymerization of the adhesive increasing the immediate bond strength. ${ }^{(42)}$

According to adhesion-decalcification concept, the bond stability depends on the formation of stable calcium salts upon interaction with HA crystals. 10-MDP was reported to form the most stable calcium salts among the functional monomers. Superficial dentin demineralization means limited decalcification which in turn did not result in complete dissolution of HA crystals but kept them in place which led to more stable calcium salts and in turn increased the bond efficacy. ${ }^{(43,44)}$ On the other hand, this result was in disagreement with 
Kamozaki et al, 2015 ${ }^{(32)}$ who concluded that, the bond strength of softened dentin was not influenced by the application of any CPP-ACP based paste types, while another one revealed increase in bond strength after remineralization of softened dentin although this increase was not statistically significant. ${ }^{(33)}$

In previous investigations where CPP-ACP was applied for 60 minutes per day and the treatment was repeated for seven days, the results reported higher bond strength values compared to the non treated group. ${ }^{(33,45)}$ Another study applied CPP-ACP for three minutes once immediately after finishing of the cavity preparation and also showed increase in bond strength. ${ }^{(34)}$ The improved micro shear bond strength was confirmed by the high frequency of adhesive failure and low frequency of mixed failure as declared in table (5). ESEM showed that the dentin pre-treatment with MI paste plus did not adversely influence the resin dentin interface as shown in figure (6) which represented a continuous, uniform and thick hybrid layer. Many resin tags impregnation penetrating into the dentinal tubules and restoration of some tubular outlines.

For Solobond $\mathrm{M}$ adhesive, after preliminary etching with phosphoric acid on the remineralized $\mathrm{CAD}$, it might remove the smear layer and the precipitation of $\mathrm{Ca}$ and $\mathrm{P}$ minerals gained from the remineralization effect led to a residue layer, which was not perfectly dissolute and removed by the action of phosphoric acid and acted as a barrier interfering the proper impregnation of the adhesive into the superficial dentin but this resin permeation was better than in the control specimens of SD. On the contrary, it showed significantly lower micro shear bond strength than that of CAD, as the phosphoric acid could remove and dissolute the intratubular precipitated crystals, resulted in better permeation of the adhesive monomer. These findings come in accordance with the study which reported that, exposure to phosphoric acid led to dissolution of intratubular dentin thus increasing the tubular diameter and decreasing the intertubuluar dentin area. ${ }^{(24)}$ Thereby, contribution of a resindentin bonding efficiency occurred. This was consistent with the studies which reported very high bond strength obtained from etching of CAD with phosphoric acid if the moist bonding technique was used. ${ }^{(33,37,46,47)}$ This was confirmed by ESEM micrographs which showed similar results to RCAD SBU \& RCAD FM+ groups but with fewer resin impregnations as shown in fig.6. The possible explanation of the decreased micro shear bond strength value of Solobond M to SD is the presence of high percentage of acetone (near to 70\%) in its composition, this may not allow to increase the monomer concentration to provide formation of uniform resin film on the etched dentin surface. ${ }^{(48)}$

However, pretreatment of CAD with CPP-ACPF adversely influenced the micro shear bond strength value of Futurabond DC $(10.648 \pm 3.887 \mathrm{MPa})$ which is non significant compared to SD group $(11.711 \pm 3.659 \mathrm{MPa})$ and statistically significant with the CAD group which showed high micro shear bond strength $(16.967 \pm 3.556 \mathrm{MPa})$. This may be attributed to the nature of CAD which is full of porosity and the active application of the adhesive enhanced its infiltration created a gradient flexible intermediate hybridization zone due to presence of nanofillers whereby the stresses at the interface induced by polymerization shrinkage transmitted and attenuated. ${ }^{(48)}$ Also, Futurabond DC contains remarkable amounts of highly functional nano sized cross linking agents which attributed to the high bond strength to dentin as claimed by the manufacturer and the silica filler particles have the merits of being dual cured. ${ }^{(11)}$

The remarkable significant decrease in micro shear bond strength after treatment of RCAD group with CPP-ACPF based paste as shown in table (3) could de due to the deposition of minerals which might occlude the dentinal tubules completely as a result of remineralization effect. Thus interfering the homogenous resin penetration specially when its $(\mathrm{pH}=2)$ and termed as mild adhesive that hardly dissolute the minerals superficially. Moreover, 
the presence of nano fillers in the adhesive might deprive the resin monomer from well penetration as it increased the viscosity even with active application. These fillers might be accumulated in a way that the outcome was a stiff, not flexible transitional zone of very superficial attachment partially compromised by the discontinuities led to uneven stress distribution and decreased microshear bond strength. These findings were confirmed by ESEM results which showed partial occlusion of some dentinal tubules which caused apparent narrowing of tubular diameter and led to impaired resin permeation inside them.

Regarding the demineralized CAD groups, it was obviously noticed that all the tested adhesives with the different strategies recorded increased micro shear bond strengths, which was significant for Solobond M and Futurabond DC (17.097 \pm 2.162 $\mathrm{MPa}$ and $16.967 \pm 3.556 \mathrm{MPa})$ and was non significant for Single bond universal and Futurabond $\mathrm{M}+(14.287 \pm 3.335 \mathrm{MPa}$ and $13.451 \pm 4.343 \mathrm{MPa})$ respectively as shown in table (3) compared to SD. This was in disagreement with different studies that recorded higher bond strength for SD than CAD. ${ }^{(10,35,36,41)}$

Confirming the statistical results, ESEM results comparing CAD to SD groups, the dentinal tubules which were regular with normal peritubular and intertubular architecture Fig.(4), showed widening of dentinal tubular outlines to the extent of being connected to some of the neighboring lateral branches. Obvious disappearance of some areas of peritubular dentine cuff could be seen with appearance of resin tags lengths. The resin tags impregnations were numerous below the hybrid layer which seemed thicker. The intertubular dentine showed apparent decrease in thickness than control Fig. (5).

Based on Hoy's solubility parameter and its relationship to the interaction between dentin adhesives, demineralized dentin and the outcome bond strength, that have been recently investigated in published articles, some reports revealed the several effects of solvent on demineralized dentin as a net result of difference in solubility parameters between the solvent and the substrate. In case of demineralized dentin, permeation of a hydrophilic monomer into the swollen collagen matrix can lead to an effective hybrid transitional layer by encapsulation and entanglement of primer polymer chains after polymerization within the collagen scaffold. The solvent can replace water in intrafibrillar spaces and thus lead to significant increase in bond strength to demineralized dentin. If complete demineralization of dentin occurs, water is still remain in the intrafibrillar spaces in wet bonding and acts as a water-bridge hydration network and kept in bound state through hydrogen bonds. This indicates that, the displacement of water in the intrafibrillar spaces restricts the penetration of the resin monomer to some extent. This variable could be of a great value to understand the permeation of the adhesive into the collagen network. Besides other additives such as functional monomers, activators, inhibitors, the amount of monomers, diluents, filler loading and shrinkage and stiffness of these filled adhesives which significantly impact the bond strength among several manufacturers' technology which is not fully described in the final formulation and still a secret. ${ }^{(11,40)}$

Analysis of the results revealed that, the microshear bond strength was affected in a positive way by dentin pretreatment with MI paste plus, which may improve the durability of the overlying bonded restorations as well as decrease the possibility to secondary caries in account of increased remineralization. This finding might be of a great relevance, although further in-vitro and in-vivo studies should be performed to prove this finding.

So, within the limitations of this study, it can be concluded:

1- Performance of the tested adhesives strategies was shown to be dentin-dependant.

2- Dentin pretreatment with CPP-ACPF containing paste affects positively the micro shear bond strength of Single bond universal and 
Futurabond M+ universal adhesives when used in self-etch mode.

3- The specific chemical formula of the tested adhesives might coordinate with the demineralized dentin.

\section{ACKNOWLEGEMENT}

The authors would like to acknowledge the assistance from Dr. Iman Naser and Dr. Dina Safwat, Lecturers of Operative dentistry, Faculty of dentistry, Ain-Shams University.

Also, great gratitude for Dr. Ashraf A. Mohamed, Professor of Analytical chemistry, and his team of staff members, Faculty of Science, Ain-Shams University for preparing the demineralizing and remineralizing solutions.

\section{REFERENCES}

1- Nakajima M, Kunawarote S, Prasansuttiporn T, Tagami J. (2011) Bonding to caries-affected dentin. Japanese Dental Science Review 47: 102-114.

2- Giriyappa HR, Chandra S B. (2008) Comparative evaluation of self-etching primers with fourth and fifth generation dentin-bonding systems on carious and normal dentin substrates: An in vitro shear bond strength analysis. J Conserv Dent 11:154-158.

3- Pinna R, Usai P, Arrica M, Milia E. (2015) Effectives of Two Self-Etchings Bonded Clinically in Caries Affected Dentin with Homogeneous Smear Layer. Journal of Nanomaterials Article ID 489183: 1-7.

4- Abou Neel AE, Aljabo A, Strange A, Ibrahim S, Coathup M,Young MA,Bozec L, Mudera V.(2016) Demineralization-Remineralization dynamics in teeth and bone.Inernational Journal of Nanomedicine,11:4743-4763.

5- Ekambaram M, Kar Yung Yiu C, Matinlinna JP. (2015) Bonding of resin adhesives to caries-affected dentin - A systematic review. International Journal of Adhesion \& Adhesives 61:21-34.

6- Vassileva R, Dyulgerova E, Gusiyska A, Mironova J, Gyulbenkiyan E.(2016) Biomimetic Approaches of Dentin Regeneration. Internaional Journal of Science and Research 5: 752-755.
7- Kunawarote S, Nakajima M, Foxton RM, Tagami J.(2011) Pretreatment effect of mild acidic HOCL solution on adhesive to caries-affected dentin using self-etch adhesive. Eur J Oral Sci 119:86-92.

8- Nakajima M, Sano H, Urabe I, Tagami J, Pashley DH. (2000) Bond strengths of single-bottle dentin adhesives to caries-affected dentin. Oper Dent25:2-10.

9- Erhardt MCG, Toledano M, Osorio R, Pimenta LA. (2008) Histomorpho-logic characterization and bond strength evaluation of caries-affected dentin/resin interfaces: effect of long-term water exposure. Dent Mater 24: 786-98.

10- Oskoee PA, Ajami AA, Oskoee SS, Pournaghi-Azar F. (2008) Microtensile Bond Strength of Single Bond and Adper Prompt-L-Pop Adhesives to Dentin. Journal of Dentistry 5:12-16.

11- Joseph P, Yadav C, Satheesh K, Rahana R. (2013) Comparative Evaluation Of The Bonding Efficacy Of Sixth, Seventh And Eighth Generation Bonding Agents: An In Vitro Study. Int. Res. J. Pharm 4:143-147.

12- Chen C, Niu LN, Xie H, Zhang ZY, Zhou LQ et al. (2015) Bonding of Universal Adhesives To Dentine-Old Wine In New Bottles?. J Dent 43:525-536.

13- Munoz MA, Luque I, Hass V, Reis A, Loguercio AD et al.(2013) Immediate Bonding Properties Of Universal Adhesives To Dentine. J Dent 41: 404-411.

14- Perdigao J, Sezinando A, Monteiro CP. (2012) Laboratory bonding ability of a multi-purpose dentin adhesive. American Journal of Dentistry 25:153-158.

15- Wagner A, Wendler M, Petschelt A, Belli R, Lohbauer U. (2014) Bonding Performance of Universal Adhesives In Different Etching Modes. J Dent 42:800-807.

16- Van LK, Landuyt, Kanumilli P, De Munck J, Peumans M, et al. (2006) Bond Strength of a mild self-etch adhesive with and without prior acid-etching.Journal of Dentistry 34:77-85.

17- Pleffken RP, Lourenco PA, Torres RC, Borges AB. (2011) Influence of application methods of self-etching adhesive systems on adhesive bond strength to dentin.Journal of Adhesive Dentistry 13:517-525.

18- Loguercio DA, Stanislawczuk R, Mena-Serrano A, Reis A. (2011) Effect of 3-year water storage on the performance of one-step self-etch adhesives applied actively on dentine. Journal of Dentistry 39:578-587. 
19- Yoshida Y, Yoshihara K, Hayakawa S, Nagaoka N, Okihara T et al. (2012) HEMA inhibits interfacial nano-layering of the functional monomer MDP. J Dent Res 91:1060-1065.

20- Donmez N, Belli S, Pashley DH, Tay FR. (2005) Ultra structural correlates of in vivo/in vitro bond degradation in self-etch adhesives. J Dent Res 84:355-359.

21- Ying Cao C, Lei Mei M, Quan-Li Li, Chin Man Lo E, Hung Chu C. (2015) Methods for Biomimetic Remineralization of Human Dentine: A systematic Review. International Journal of Molecular Sciences 16:4615-4627.

22- Han M, Lili Q,Cao Y, Fang H, Xia R, Hong Zhang Z.(2017) In vivo remineralization of dentin using an agarose hydrogel biomimetic mineralization system.Scientific reports. www.nature.com 1-9.

23- Epasinghe JD, Yiu YC, Burrow FM. (2015) Synergistic effect of proanthocyanidin and CPP-ACP on remineralization of artificial root caries. Australian Dental Journal 60:463-470.

24- Denewar MEM, Negm EAA, El Zehary ARR, Radwan SRL, Elhawary AMY. (2014) Impact of Topically PEPSI Drink on Enamel and Dentin Surfaces with and without Application of "Casein Phosphopeptide-Amorphous Calcium Phosphate with Fluoride". Mansoura Journal of Dentistry 1:90-95.

25- Zhang X, Xiao Z, Wang H, Kishen A. (2016) Biomineralization and Biomaterial Considerations in Dentin Remineralization. Journal of Operative Dentistry and Endodontics 1:7-12.

26- Mittal R,Relhan N,Tangri T(2017)Remineralizing agents:A comprehensive review. Int.J.Clin Prev Dent 13:1-4.

27- Muller GEW, Ackermann M, Neufurth M, Tolba E, Wang S, Feng Q, Schroder CH, Wang X. (2017) A Novel Biomimetic Approach to Repair Enamel Cracks/Carious Damages and to Reseal Dentinal Tubules by Amorphous Polyphosphate. Polymers 9:1-20.

28- Jen-Chang Yang, Hsin-Taittu, Lee SY, Hsieh SC, Huang PC, Ma CF, Ji DY, Chang LY, Teng CN.(2017) In Vitro Evaluation of Dentin Tubule Occlusion for Novel Calcium Lactate Phosphate (CLP) Paste. Materials 10:1-7.

29- Diamanti I, Koletsi-Kounari H, Mamai-Homata E. (2016) Effect of tooth pastes containing different $\mathrm{NaF}$ concentrations or a $\mathrm{SnF}_{2} / \mathrm{NaF}$ combination on root dentin erosive lesions, in vitro. J Clin Exp Dent: 1-7.
30- Rahiotis C, Vougiouklakis G. (2007) Effect of a CPP-ACP agent on the demineralization and remineralization of dentin in vitro. J Dent 35:695-698.

31- Kshirsagar PS, Aggarwal S, Gupta RP, Mukhtar A. (2015) Comparrative assessment of bond strengths of affected dentin, using two different remineralizing solutions with or without lasers: Results of an in vitro pilot study. Journal of Research in Dental Sciences 6:82-86.

32- Kamozaki BBM, Prakki A, Perote CCL, Gutierrez CN, Pagani C. (2015) The effect of CPP-ACP and Nd:YAG laser on the bond strength of softened dentin. Braz Oral Res 29:1-7.

33- Adebayo OA, Burrow MF, Tyas MJ. (2010) Resin-dentine interfacial morphology following CPP-ACP treatment. J Dent 38:96-105.

34- Borges DCB, Souza-Junior JE, Da Costa ADG, Pinheiro AVI, Sinhoreti CAM, et al. (2012) Effect of dentin pretreatment with casein phosphopeptide-amorphous calcium phosphate (CPP-ACP) paste on dentin bond strength in tridimensional cavities. Acta Odontologica Scandinavia: 1-7.

35- Lenzi LT, Calvo BFA, Tedesco KT, Ricci AH, Hebling J, et al. (2015) Effect of method of caries induction on aged resin-dentin bond of primary teeth. BMC Oral Health15:1-6.

36- Erhardt GCM, Lobo MM, Goulart GM, Coelho-de-Souza HF, Valentino AT, et al. (2014) Microtensile bond strength of etchand-rinse and self-etch adhesives to artificially created carious dentin. Caries Detection and Prevention: 56-61.

37- Sonoda H, Banerjee A, Sherrif M, Tagami J, Watson FT. (2005) An in vitro investigation of microtensile bond strengths of two dentine adhesives to caries affected dentine. Journal of Dentistry 33:335-342.

38- Ceballos L, Camejo DG, Fuentes MV, Osorio R, Toledano M. (2003) Microtensile bond strength of total-etch and self-etching adhesives to caries-affected dentine. Journal of Dentistry 31:469-477.

39- Lenzi LT, Tedesco KT, Soares MZF, Loguercio DA, Rocha OR. (2012) Chlorhexidine does not Increase Immediate Bond Strength of Etch-and-Rinse Adhesive to Caries-Affected Dentin of Primary and Permanent Teeth. Braz Dent J 23:438-442.

40- Vaidyanathan KT, Vaidyanathan J. (2009) Recent Advances in the Theory and Mechanism of Adhesive Resin Bonding to Dentin: A Critical Review. J Biomed Mater Res Part B: Appl Biomater 88B:558-578. 
41- Yoshiyama M, Tay RF, Doi J, Nishitani Y, Yamada T, et al. (2002) Bonding of Self-etch and Total-etch Adhesives to Carious Dentin. J Dent Res 81:556-560.

42- Iwai H, Nishiyama N. (2012) Effect of calcium salt of functional monomer on bonding performance. J Dent Res 91:1043-1048.

43- Van Landuyt K, Yoshida Y, Hirata I, Snauwaert J, De Munck J, et al. (2008) Influence of the chemical structure of functional monomers on their adhesive performance. $\mathrm{J}$ Dent Res 87:757-761.

44- Milia E, Cumbo E, Jose A, Cardoso R, Gallina G. (2012) Current Dental Adhesive Systems. A Narrative Review. Curr Pharm Des 18:5542-5552.
45- Adebayo OA, Burrow MF, Tyas MJ. (2008) Dentin bonding after CCP-ACP paste treatment with and without conditioning. J Dent 36:1013-1024.

46- Ceballos L, Camejo DG, Fuentes MV, Osorio R, Toledano M, et al. (2003) Bonding of Self-Etching Adhesives to Caries-Affected Dentin. J Dent 31:469-477.

47- Yoshiyama M, Doi J, Nishitani Y, Itota T,Franklin R, et al. (2004) Bonding Ability of Adhesive Resins To Caries-Affected and Caries-Infected Dentin. J Appl Oral Sci 12:171-176.

48- Lopes GC, Cardoso PC, Vieira CCL, Baratieri LN, Rampinelli K. (2006) Shear Bond Strength of Acetone-Based One-Bottle Adhesive Systems. Braz Dent J 17:39-43. 